\title{
Behavioural public policies and charitable giving
}

\author{
LUC BOVENS
}

Department of Philosophy, University of North Carolina at Chapel Hill, NC, USA.

\begin{abstract}
Some of the challenges in Sanders et al. (2018, this issue) can be aptly illustrated by means of charity nudges; that is, nudges designed to increase charitable donations. These nudges raise many ethical questions. First, Oxfam's triptychs with suggested donations are designed to increase giving. If successful, do our actions match ex ante or ex post preferences? Does this make a difference to the autonomy of the donor? Second, the Behavioural Insights Team conducted experiments using social networks to nudge people to give more. Do these appeals steer clear of exploiting power relations? Do they respect boundaries of privacy? Third, in an online campaign by Kiva, donors are asked to contribute directly to personalised initiatives. In many cases, the initiative has already been funded and donor money is funnelled to a new cause. Is such a 'pre-disbursal' arrangement truthful and true to purpose as a social business model?
\end{abstract}

Submitted 11 December 2017; revised 24 February 2018; accepted 2 March 2018

\section{Introduction}

Sanders et al. (2018, this issue) present a wide range of challenges in behavioural public policy-making. I will focus on how some of these issues play out in nudges to increase charitable giving and will explore the concomitant ethical problems. The authors point out that many of the early trials in behavioural policy-making were focused on compliance and in particular on "one-off behaviours with binary desirable decisions." Charity nudges do not fit this mould. They are about increasing the value of a continuous variable over time; namely, the amount of charitable donations. And if nudging can be harnessed to increase donations raised, then it is no longer, in the authors' words, "low-hanging fruit". 


\section{Unstructured repetitions and three-window charity campaigns}

Sanders et al. (2018) discuss the long-term effects of "unstructured repetitions" of behavioural techniques; that is, techniques that are repeatedly implemented in different campaigns and policy domains. Consider an example of what could easily become an unstructured repetition in charity nudges, viz. Oxfam's triptych strategy. It works as follows: prominently placed on its homepage, Oxfam (2018) has three pre-set donation amounts, along with a fourth option to name your own. This setup encourages donors to choose the middle amount by taking advantage of our inclination to avoid extremes. The highest suggested amount, we might think, is for those richer than ourselves. But we also don't want to be seen giving the lowest amount. Hence, like Goldilocks, we go for the middle one. But this middle one is substantially higher than what most people would donate without the triptych set-up.

Oxfam changes around the amounts in the boxes. Sometimes the middle and higher amounts are round numbers and the lower amount is a number that has less face recognition. This is the mere exposure effect of Zajonc (1968) at work: we shy away from unfamiliar numbers - in this case, monetary amounts that, if we were to pay in cash, would require scrambling together bills and coins. Or sometimes the lower amount is just so embarrassingly low that donors won't choose it.

Will this strategy keep being successful when different charities start applying the same trick? It is of course an old trick of commercial advertising. Or will people just revert to giving however much they would have given in the absence of the triptych set-up? This is an open question and requires empirical research.

But suppose that it keeps on working - then we might ask: why don't donors come to realise that they are being tricked into giving more than they would have given otherwise? After all, it's not too difficult to see what is going on. Maybe people don't mind a bit of trickery because they really do want to give more to charity and this nudge helps them to do so. And furthermore, nobody is asking for their money back.

There are two ways in which the campaign's nudge might be helping donors do what they want to do. First, donors may, ex ante, want to give more to charity. This is like wanting to quit smoking. They are happy to get all the help that they can get. Second, donors may, ex post, feel good about having given a bit more to charity. It's not that they initially wanted to give that much. But they were tricked by the triptych set-up into doing so, and it is to avoid cognitive dissonance that they take ownership of their otherwise inexplicable decision. That is, donors look back on how much they gave and do not recognise (or refuse to recognise) the efficacy of the triptych set-up. To make sense of why they gave this much, they self-identify as being generous 
people. It is at this point that they say that they simply wanted to give as much as they did.

When the desire is ex ante, then the long-term effect is supported by the fact that the nudge just helped us more easily do what we wanted to do deep down anyway. We just failed to realise this earlier due to inertia, or maybe, in the case of charitable donations, due to greed. Now that we have given once, the ice is broken, we see a path and we continue giving. In this case, I don't see any violation of autonomous agency, even if we are not fully conscious of the fact that we are being nudged towards achieving our goals.

When the desire is ex post, then the long-term effect is supported by the fact that our self-identification hinges on rationalising our charitable giving, while the charitable giving itself was caused by a behavioural mechanism. This process may well lead to a more generous disposition, which might be welcome. Nonetheless, when the mechanism of cognitive dissonance reduction is at work, we refuse to recognise the true drivers of our agency and shift our self-conception to make our actions seem coherent. This is hardly a model of autonomous agency.

Aside from the empirical question of whether this kind of nudging has long-term effects, there are ethical questions to be asked. Is it the case that the nudges just help us do what we always really wanted to do; that is, to give more to charity? Or do they steer us towards actions that cause us to think of ourselves as generous people - as people who want to give to charity? The latter seems more problematic than the former, even though we do end up in an equally good place.

\section{Networking and reach campaigns}

Sanders et al. (2018) argue that behavioural public policy should take more of an interest in harnessing the power of social networks. The messenger effect plays an important role in social networks; that is, when trying to get others to adopt a certain behaviour, it matters very much who provides the information or offers the counsel. If the person is trusted, we will meet with much greater uptake of the targeted behaviour. For example, the Cabinet Office publication MINDSPACE (2010) describes cases in which high schools invite former students - as opposed to professionals - to give talks discouraging teenage pregnancies and in which reformed ex-convicts are invited to mentor at-risk youth.

Sanders et al. (2018) cite two examples of experiments by the Behavioural Insights Team involving social networks in charitable giving. In an experiment in the London branch of Deutsche Bank, they found that personalised (rather than anonymous) messages from the CEO suggesting donations to particular charities were highly efficacious. In a later experiment, mid-level managers in an investment bank who had previously donated were asked to reach out to 
colleagues and encourage them to give to charity or to tell them in addition about the huge impact their charitable contributions can make. Again, these interventions had a positive effect on donations (Cabinet Office, 2013; Behavioural Insights Team, 2015).

None of this is too surprising. If your boss writes to you, addressing you by name and asking you to donate to a particular charity, it would require some courage to say no. In the later experiment, it is not clear what the rank is of the colleague to whom these mid-level managers are asked to write. But no matter one's rank, it would be hard to ignore such appeals if one wants to secure a good atmosphere in the workplace.

These experiments have radically different ethical dimensions than the programmes listed under MINDSPACE. In the latter programmes, we line up respected and trusted others to deliver a positive message. But the success of the experiments of the Behavioural Insights Team depends more on exploiting power relations, both obvious and subtle. CEOs decide raises and promotions. Co-workers depend on mutual favours in the workplace. Office workers want to ingratiate themselves by giving in to requests for charitable giving.

What is morally problematic is that there is a mixing of spheres. The CEO has no business putting pressure on employees in matters that are not work related. To each their own: employees may wish to donate to other charitable causes, or they may not wish to donate to charities at all. Furthermore, asking employees who have given to charity before to reach out and encourage others to donate is a violation of privacy. I don't want to be cornered in the workplace by requests for charitable giving. I might make an exception for some bake sale or something equally light-hearted, but I can find my own way to, say, the Oxfam website if I wish to donate. This is not to say that businesses should not themselves provide opportunities for charitable giving or volunteering. But providing opportunities is different from the CEO promoting charitable causes or asking those who have already bought into these causes to proselytise to others.

Sanders et al. (2018) may be right in observing that we have done little work in exploring how to harness social networks in policy interventions. But given what we know about how this approach has been applied in the domain of charitable giving, we should be wary of abuse of power and violations of privacy.

\section{Online campaigns and social diffusion}

Sanders et al. (2018) do not touch on online campaigning, but this is an allimportant tool for social diffusion, and behavioural techniques are at the core of many of these campaigns.

The website of Kiva (2018a) provides an interesting example. Donors are asked to contribute to a micro-loan for, say, a particular farmer, identified 
by name, in the developing world who needs funding to put in their crops. We feel a sense of collective purpose - together, we can make it possible that this poor farmer will be able to succeed. There are always a few loans on the website that are close to their targets. So, it's in our hands to make things happen. There is the immediate gratification of having made a difference: because of our contribution, the beneficiary has reached their target and they are ready to take off to the field now. What is at work is both a herd effect and an immediacy effect. And furthermore, we are motivated because we feel a personal responsibility in a situation in which our contribution will be pivotal.

However, when we do a more careful read of how Kiva works, we learn that the reality is somewhat different:

For most loans on Kiva, our local Field Partners are responsible for distributing the funds to borrowers. Depending on the Field Partner, the funds may be given to each borrower before, during, or after the individual loan is posted on Kiva. Most partners give the funds before the loan is posted (what we call pre-disbursal) because it allows the borrowers to use the funds immediately. So when a lender supports a partner loan on Kiva, the borrower may already have the funds in hand (Kiva, 2018b).

In other words, the person whom you think you are helping has long before received their funding. Kiva's Field Partner has chosen this person for a picture and a story for the Kiva website, with a running tally of donations that will eventually add up to the total amount that was lent to this person a few months ago.

Is this deceptive? I am not sure what to say.

On the one hand, there are certainly many donors who genuinely believe that it is because of their donation that a particular beneficiary is off to the field today. This is what motivates them to give. And if the donation had been described more accurately - say, as intended to keep a programme running that supports a wide array of micro-loans, with some earlier projects as examples - they might not have been motivated to give at all.

On the other hand, Kiva does lay out on its website how it operates, although it does require clicking through twice - first to 'How Kiva Works' and second to 'How does the money for the loan get to each borrower?' Furthermore, shouldn't it be obvious that some farmer on the other side of the world isn't twiddling their thumbs waiting to plant until the tally has reached its target? Clearly, this would be an ineffective social business model. The website is just a bit of make-believe to create the illusion that there is a direct connection between a donation and the benefit to a particular farmer. Any reflective person 
can figure out what's going on. And who could object to a bit of fun in playing along with this illusion?

The Fundraising Regulator (2016) in the UK imposed a strict Code of Good Practice to constrain 'chugging' on the high street, door-to-door fundraising and direct mail campaigns. The Code specifies that charity campaigns should be both truthful and true to purpose; that is, they should not ask us to donate to buy a goat for a farmer in Africa and then use our donations for overheads instead. This would clearly not be true to purpose. But is 'pre-disbursal' truthful and true to purpose? Is it truthful and true to purpose to ask people to join in with the crowd or to provide the pivotal dollar in support of projects that were actually funded many months before? Is Kiva sailing close to the wind? I leave this for the reader to judge.

\section{Acknowledgements}

I am grateful to Ian Hower and Miriam Johnson for comments on earlier drafts of this paper.

\section{References}

Behavioural Insights Team (2015), The Behavioural Insights Team Update 2013-2015. [Online] Available at: http://www.behaviouralinsights.co.uk/publications/the-behavioural-insights-teamupdate-report-2013-2015/ [Accessed 17 Feb. 2018].

Cabinet Office (2010), MINDSPACE_Influencing Behaviour through Public Policy. [Online] Available at: https://www.instituteforgovernment.org.uk/publications/mindspace [Accessed 17 Feb. 2018].

Cabinet Office (2013), Applying Behavioural Insights to Charitable Giving. [Online] Available at: https://www.gov.uk/government/publications/applying-behavioural-insights-to-charitablegiving [Accessed 17 Feb. 2018].

Fundraising Regulator (2016), Code of Fundraising Practice. [Online] Available at: https://www.fundraisingregulator.org.uk/code-of-fundraising-practice/code-of-fundraising-practice-v1-4-310717docx/ [Accessed 17 Feb. 2018].

Kiva (2018a), Kiva-Lend-Agriculture. [Online] Available at https://www.kiva.org/lend/agriculture [Accessed 17 Feb. 2018].

Kiva (2018b), Kiva - How Kiva Works - How does the money for the loan get to each borrower? [Online] Available at: https://www.kiva.org/about/how [Accessed 17 Feb. 2018].

Oxfam, (2018), Oxfam. Donate. [Online] Available at: https://www.oxfam.org.uk/donate [Accessed 17 Feb. 2018].

Sanders, M., V. Snijders, and M. Hallsworth (2018), 'Behavioural science and policy: where are we now and where are we going?', Behavioural Public Policy, 2(2): 144-167.

Zajonc, R. B. (1968), 'Attitudinal Effects of Mere Exposure', Journal of Personality and Social Psychology, 9(2): pp. 1-27. 